\title{
A escola agora é outra: o Programa de Assistência Brasileiro Americana ao Ensino Elementar - PABAEE (1956 a 1964)
}

\author{
Susane da Costa Waschinewski* \\ Universidade do Estado de Santa Catarina \\ Giani Rabelo** \\ Universidade do Extremo Sul Catarinense
}

Resumo Esta pesquisa tem como objetivo analisar o filme $A$ escola agora é outra produzido no âmbito do Programa de Assistência Brasileiro-Americana ao Ensino Elementar (PABAEE), a fim de evidenciar o programa e os discursos educacionais que envolveram o mesmo. A pesquisa tem como recorte temporal os anos de 1956 a 1964, período de vigência do convênio entre Brasil e Estados Unidos. Tal acordo tem início no governo de Juscelino Kubitschek (1956 a 1961), momento em que o país era tomado pelo discurso de cunho nacional desenvolvimentista, pautado em uma política que apregoava e estimulava o crescimento econômico. Esta política buscou redimensionar vários setores e suas funções, sendo que a educação foi um deles. O filme $A$ escola agora é outra não apenas apresentou o PABAEE como uma solução dos problemas para educação brasileira, buscando reforçar o papel que a escola deveria cumprir no processo de modernização e a centralidade do trabalho da professora, mas apontou para a necessidade de uma nova escola, com métodos ativos, com equipamentos escolares adequados, evidenciando que a escola vigente estava atrasada e era pouco atrativa. Além disso, culpabilizou a professora primária pelos baixos índices educacionais.

PALAVRAS-CHAVE: PABAEE; Professora primária; Ensino Elementar. 


\title{
School now is another: the Program of American Brazilian Assistance to Elementary Education - PABAEE (1956 a 1964)
}

\begin{abstract}
This is the most complete version of the Brazilian-American Assistance to Elementary Education program (PABAEE), in order to highlight the program and the educational discourses that have involved the same. The research has as temporal cut of the years of 1956 to 1964, period of validity of the agreement between Brazil and the United States. There is no government of Juscelino Kubitschek (1956 to 1961), when the country was taken over by the national developmentalist discourse, based on a policy that preached and stimulated economic growth. This policy sought to reshape various sectors and their functions, and education is yours. The film The School is now more than just presented PABAEE as a solution of the problems for Brazilian education, seeking to strengthen the role for the academy, as well as the labeling of processes of modernization and centrality of the teacher's work, but pointed to the need for a new school, raw materials, adequate school items, showing that the current school was late and unattractive. In addition, she blamed a primary teacher for low educational rates
\end{abstract}

KEYWORDS: PABAEE; Primary; Teacher; Elementary Education.

\section{Introdução}

Nos primeiros passos dados na realização do projeto de pesquisa Desenvolvimento, Educação e Planejamento em Santa Catarina (1955-2010) ${ }^{1}$ foram surgindo inúmeras questões, entre elas o interesse em saber como as políticas desenvolvimentistas e de modernização incidiram sobre o processo educacional brasileiro. Nos primeiros levantamentos de documentos, chamou nossa atenção o discurso de cunho nacional desenvolvimentista, no tocante à necessidade de formar da mão de obra qualificada, à expansão do ensino, aos investimentos na educação e à formação de professores/as, bem como os acordos políticos e financeiros com o capital estrangeiro, principalmente com o governo dos Estados Unidos.

Ao pesquisarmos algumas campanhas e convênios educacionais realizados pelo governo brasileiro no início dos anos de 1950 e 1960 foi possível identificar várias iniciativas governamentais, entre elas o Programa de Assistência Brasileiro-Americana ao Ensino Elementar (PABAEE).

Importante destacar que nas referidas décadas, o viés desenvolvimentista se expressava no contexto político, econômico e cultural pelos ideais de modernização, já praticadas no governo de Getúlio Vargas (1930-1945) e de Juscelino Kubitschek (1956 a 1961) com uma nova roupagem.

Em relação ao cenário nacional, após a eleição de Juscelino Kubitschek, em 1956, o então presidente lança seu plano de governo chamado de Programa de Metas, que almejava vastos investimentos nos setores de energia, transportes, alimentação, indústrias de base e incentivo à indústria automobilística. 
A marca de Juscelino para concretizar essa política de modernização foi desenvolvida sob o slogan "cinquenta anos em cinco", política que previa o crescimento e desenvolvimento econômico do país em cinco anos, o que transcorreria em cinquenta anos. Essas metas só poderiam ser materializadas por meio da ação governamental pautadas no Programa de Metas, nessa concepção compreendia-se o estado como planejador, com o poder de pensar, intervir e regular, realizando diversas políticas setoriais, inclusive educacionais.

Para Ianni (1996), o Programa de Metas visava transformar a estrutura econômica do país alicerçada em investimentos para a criação de indústrias de base e a reformulação das condições reais de interdependência com o capitalismo mundial. O desdobramento desse novo processo implicou na emergência de novas situações, gerando assim a necessidade de mão de obra qualificada, ou seja, homens e mulheres alfabetizados/as e instruídos/as que pudessem trabalhar na indústria brasileira.

Diante desse novo contexto foi necessário pensar na formação da mão de obra trabalhadora, bem como nas políticas que pudessem solucionar tais carências de maneira rápida. A necessidade de resolver essa carência pautou a educação como "carro-chefe" no processo de desenvolvimento e modernização da sociedade brasileira, ganhando destaque o discurso do binômio Educação para o Desenvolvimento. Assim, alguns investimentos ocorreram no campo educacional, inclusive no pacote direcionado à assistência à América Latina, implantados pelo governo norte americano.

Segundo Paiva e Paixão (2002, p. 61), a partir do "acordo sobre Serviços Técnicos Especiais, o governo americano concordou em colocar à disposição do governo brasileiro serviços técnicos". Um dos focos dessa assistência era o ensino secundário (organizado em dois ciclos: o primeiro de quatro anos, conhecido como ginásio, e o segundo ciclo de três anos, chamado de Colégio), ligado diretamente à formação industrial. Desse modo, o acordo foi denominado de Programa de Assistência Brasileiro-Americana à Educação de Ensino Secundário (PABAEES) (PAIVA; PAIXÃO, 2002).

Não obstante, era visível que os desafios educacionais eram enormes e que a assistência apenas ao ensino secundário não garantiria os resultados esperados, pois se acreditava que as defasagens partiam de processos educacionais anteriores, os quais deveriam ser repensados, como a própria formação de professores/as. Logo o programa volta-se para a experiência do Ensino Elementar brasileiro.

Em 1956, no início do governo de Juscelino, tendo como secretário da Educação e Cultura Clóvis Salgado², foi assinado o acordo para a execução do Programa de Assistência Brasileiro-Americana ao Ensino Elementar (PABAEE), que tinha como prioridades: a) formar professores do ensino normal, b) elaborar materiais didáticos, c) enviar aos Estados Unidos professores de ensino normal e elementar para realizar curso de aperfeiçoamento (PAIVA; PAIXÃO, 2002).

Com esta finalidade, no PABAEE é elaborado um filme intitulado $A$ escola agora é outra ${ }^{3}$, sendo este objeto de análise deste artigo. A escolha do filme está dentro do movimento de alargamento promovido no campo História Cultural, em que as 
linguagens visuais têm conquistado um espaço relevante no campo da pesquisa em História e Historiografia da Educação.

Neste trabalho, nos propomos a analisar o referido filme, entendendo que, como documento histórico, ele pode oferecer elementos importantes na compreensão do que se desejava com o PABAEE quanto a formação das professoras primárias, obviamente que tal filme estava encharcado de intenções e era condutor de um discurso que almejava propagar o modelo educacional norte americano para a América Latina.

Nesse sentido, é fundamental analisá-lo como um documento circunscrito no contexto em que foi produzido, a fim de entender seus usos e omissões e os porquês delas, além de perceber que público pretendeu atingir. Nesta perspectiva, um documento só se torna um documento histórico quando o pesquisador passa a fazer perguntas a ele, caso contrário é só mais um indício. Ademais, concordamos com Le Goff (2003) quando afirma que todo documento é um monumento. Para ele, todo documento tem em si um caráter de monumento, pois não existe memória coletiva bruta. "O documento não é qualquer coisa que fica por conta do passado, é um produto da sociedade que o fabricou segundo as relações de força que aí detinham o poder". (LE GOFF, 2003, p. 543).

Napolitano (2005) aponta que o uso dos documentos audiovisuais tem apresentado um crescente aumento. Do ponto de vista metodológico os usos dessas fontes são considerados desafiadores, pois criam tensões entre duas visões "objetivista" e a "subjetivista", que por um lado confere o documento estético e, portanto subjetivo:

Sua natureza técnica, sua capacidade de registrar e, hoje em dia, de criar realidades objetivas, encenadas num outro tempo e espaço, remetem, por outro lado, a certo fetiche da objetividade e realismo, reiterado no pacto que os espectadores efetuam quando entram numa sala de cinema ou ligam um aparelho de televisão. A força das imagens, mesmo quando puramente ficcionais, tem a capacidade de criar uma "realidade" em si mesma, ainda que limitada ao mundo da ficção, da fábula encenada e filmada. (NAPOLITANO In: PINSKY, 2005, p. 235-6).

Ao arriscar aproximações do filme com um texto e seus efeitos, vale destacar uma das reflexões de Roger Chartier (1992). Na sua acepção, mesmo havendo por parte do autor ${ }^{4}$ a construção de várias estratégias para garantir uma determinada forma de compreensão do texto, mesmo o leitor ${ }^{5}$ sendo sempre visto pelo autor como obrigatoriamente sujeito a um único significado e a uma interpretação permitida, não há uma leitura única, pois o texto não tem uma eficácia absoluta. Nessa perspectiva, existe uma relação de tensão permanente entre texto e leitor, causada pelo ato que apreende e decifra o texto (CHARTIER, 1992).

Chartier (1992, p. 220) também adverte que "nenhum texto existe fora do suporte que lhe confere legibilidade; qualquer compreensão de um texto, não importa de que tipo depende das formas com as quais ele chega até seu leitor". Para ele, as obras adquirem sentido mediante um processo complexo que implica a apreciação da relação entre três plos: o texto, o objeto que o comunica e o ato que o apreende (CHARTIER, 
1992). No caso do filme A escola agora é outra, havia o intuito de prescrever modos de ensinar com o objetivo de melhorar os índices educacionais, no entanto não havia o controle sobre a forma como tais prescrições foram aprendidas e praticadas pelas professoras que tiveram acesso a ele no seu processo de formação no PABAEE.

A fim de discutir o áudio visual em questão apresentaremos primeiramente, alguns aspectos sobre o PABAEE, suas estratégias de formação para em seguida apresentar alguns aspectos analisados.

\section{Considerações sobre o PABAEE: resistências e estratégias de formação}

O início do funcionamento do PABAEE foi marcado por muitas polêmicas, em razão de que muitos acreditavam que a presença de especialistas vindos dos Estados Unidos para orientar o ensino iria reforçar a transmissão da cultura estadunidense. Os que se posicionaram favoráveis tratavam como uma ajuda para melhorar o ensino primário do país. Grande parte desse embate ocorreu com a Igreja Católica, que via no Programa uma ameaça, em função da importação da pedagogia pragmatista de Dewey, além das ideias de laicização do ensino, que no olhar dos católicos, não estavam em harmonia com o ensino brasileiro.

As tensões no campo educacional, já vinham ocorrendo desde os anos de 1920 e 1930 no contexto dos debates em torno da necessidade de criação da primeira a Lei de Diretrizes e Bases da Educação (LDB), que levou 13 anos para ser aprovada, por conta dos conflitos entre a defesa da escola pública laica e para todos, e o setor educacional privado confessional.

Oposições também se constituíram, ao longo das campanhas educacionais desenvolvidas no país, no caso do PABAEE uma das oposições mais douradoura foi formada por algumas professoras que se opuseram aos métodos de ensino empregados pelo Programa. A oposição tomava como referência os métodos de alfabetização utilizados e defendidos pela professora Lúcia Casasanta ${ }^{6}$ que defendia o método global, diferente do método adotado pelo PABAEE.

Segundo Paiva e Paixão (2002), o contexto do acordo que previu a realização do PABAEE surgiu a partir da Doutrina Truman, que pautava a segurança nacional em uma firme política contra a expansão do socialismo soviético. Harry Truman, presidente dos Estados Unidos (1945-1953), em discurso de posse de seu segundo mandato anunciou quatro pontos fundamentais para a condução da política externa norte-americana. Os três primeiros pontos eram reafirmações de políticas já adotadas em seu primeiro mandato conforme o que ficou estabelecido na Convenção sobre o Banco Internacional para a Reconstrução e Desenvolvimento:

O primeiro ponto consiste em prestar decisivo apoio às Nações Unidas e aos órgãos que lhe estão subordinados; o segundo, na continuação de programas de restauração econômica de várias nações como o Programa de Restauração Europeia (ERP) e o de acordos de reciprocidade comercial; o terceiro, no fortalecimento das nações amantes da liberdade contra os perigos de agressão; e o quarto 
(donde o nome deste programa) na assistência aos países economicamente atrasados, fornecendo-lhes meios técnicos e, mediante sua cooperação, estimulando a inversão de capital nesses países (BRASIL. No $21.177,1946)$.

Em relação ao quarto ponto, Truman (apud Black, 1968, p. 28):

Devemos pôr em execução um novo programa audaz, para que os benefícios de nossos avanços científicos e progresso industrial sejam colocados à disposição do melhoramento e crescimento das regiões subdesenvolvidas. [...] Acredito que temos de colocar à disposição dos povos amantes da paz os benefícios de nosso acervo de conhecimento técnico, a fim de ajudá-los a realizar suas aspirações para uma vida melhor. E, em cooperação com outras nações, devemos fomentar o investimento de capital nas regiões que necessitam de desenvolvimento [...].

Nesse discurso fica declarada a política norte-americana de assistência às áreas economicamente subdesenvolvidas. É a partir, então, do Programa Ponto IV que foram previstos inúmeros desígnios de assistências técnicas aos países latino-americanos, a fim de tornar o Brasil e os demais países atendidos grandes mercados consumidores, a partir de uma dominação pacífica e por via cultural.

Entre os acordos bilaterais firmados entre Brasil e Estados Unidos estavam o Acordo Geral de Cooperação Técnica, que foi assinado em 1950, e o Acordo Especial de Serviços Técnicos, com data de 30 de novembro de 1953, ambos estabelecidos entre o Ministério de Educação e Cultura e o United States Operation Missionto Brazil (USOM).

Com a posse de Juscelino Kubitschek de Oliveira (31 de janeiro de 1956) é quando começam a funcionar oficialmente os acordos homologados pelo Congresso brasileiro (NOGUEIRA, 1989). Sob o governo do referido presidente foi oficializado o acordo entre Brasil e Estados Unidos para a execução do PABAEE, assinado em 22 de junho de 1956, pelo Ministro da Educação, pelo governador do Estado de Minas Gerais $^{7}$ e pelo diretor Willian E. Warne, da United States Operation Missionto Brazil. O Programa teve como sede o Instituto de Educação de Belo Horizonte (MG), no período de 1956 a 1964, normatizado pela Portaria do MEC no 7 de 1957 e pelo Decreto Legislativo no 16 de 1965 (PAIVA; PAIXÃO, 2002).

Coube ao Instituto Nacional de Estudos Pedagógicos - INEP, vinculado ao Ministério de Educação e Cultura - MEC, a execução do Programa, garantindo sua implantação e acompanhamento. O governo federal, por intermédio do INEP, comprometeu-se a custear a suplementação de salários dos técnicos brasileiros, as passagens de ida das professoras brasileiras aos EUA, as bolsas de estudos e transportes, a compra de materiais e sediar espaços para a realização das formações em seus prédios, sendo que o INEP apoiou o Programa com a doação de livros e material didático (PAIVA; PAIXÃO, 2002). Acerca deste aspecto cabe a seguinte reflexão: se o Brasil arcou com tantas responsabilidades quais foram as contribuições e investimentos dos Estados Unidos no convênio? 
O INEP também coordenava os Centros Regionais de Pesquisas - CRPs, que se constituiu em importantes centros para a realização de pesquisas nas temáticas educacionais com a utilização de pressupostos teóricos e metodológicos das ciências sociais. Assim, a educação era tida como um dos aspectos sociais que necessitava de efetivas mudanças para se contribuir no processo de desenvolvimento e democratização da sociedade brasileira. Nesse período, o INEP tinha como diretor Anísio Teixeira (1952-1964), que já havia realizado inovações com a reforma educacional realizadas por ele na Bahia (1924) e que iria mais tarde se caracterizar na abordagem escolanovista de currículo e ensino.

A escolha do estado mineiro para o funcionamento do convênio, justifica-se pelo objetivo de reviver a Escola de Aperfeiçoamento ocorrida em Belo Horizonte nos anos de 1920 e que levou a cidade ao título de Capital Pedagógica do Brasil, durante os anos da reforma de Francisco Campos ${ }^{8}$ (PAIVA; PAIXÃO, 2002), além de ser o estado natal de Juscelino Kubitscheck.

O local que abrigou o PABAEE foi o Instituto de Educação, o qual cedeu parte de sua estrutura para o funcionamento do Programa. Após a realização de reformas e compras de equipamentos, a assistência começa a funcionar no ano de 1957, com a chegada dos técnicos vindos dos EUA.

Em relação aos departamentos, foram criados oito no total, que deveriam garantir o funcionamento do Programa, sendo que "o departamento de currículo e supervisão era responsável pela organização de cursos sobre currículo, bem como pela assistência técnica, em questões curriculares, às autoridades educacionais dos estados" (MOREIRA, 1990, p. 110).

Os objetivos do PABAEE consistiam na melhoria do ensino primário indicado para a necessidade de superação do problemático quadro da época, a fim de diminuir os índices de evasão e elevado número de repetência, suprir a necessidade de treinamento de professores das escolas primárias e normais de todo país e produção de materiais didáticos. Para conhecer os objetivos do Programa trazemos a apresentação, na íntegra, contida nos manuais da coleção Biblioteca de Orientação da Professora Primária9:

O Programa de Assistência Brasileiro-Americano ao Ensino Elementar (PABAEE) é um órgão conjunto do governo federal do Brasil, do governo de Minas Gerais e do governo dos Estados Unidos da América do Norte, destinado ao aperfeiçoamento de professôres.

Conjuntamente administrado e financiado, de acordo com os convênios do Ponto IV de 1953 e 1956, o PABAEE está localizado no Instituto de Educação de Minas Gerais, em Belo Horizonte.

São os seguintes os objetivos do PABAEE:

1. Aperfeiçoar grupos de professores para escolas normais do Brasil, e orientadoras do ensino primário.

2. Produzir ou adaptar materiais didáticos para serem usados nos treinamentos de professôres, e distribuí-los. 
3. Selecionar professôres competentes a fim de enviá-los aos Estados Unidos para um curso em educação elementar.

O trabalho primordial do PABAEE, atendendo a seu principal objetivo, que é o aperfeiçoamento de professôres, se realiza através de cursos. Já foram ministrados, aproximadamente, 40 cursos a mais de 3.500 professôres de vários Estados e Territórios brasileiros e ainda a alguns professôres do Paraguai, bolsistas do Ponto IV - Paraguai.

O PABAEE ministra, anualmente, dois cursos com duração de um semestre, com início em princípios de fevereiro e em fins de julho, a professôres de escolas normais, ou professôres que exerçam ou venham a exercer cargos de orientação técnica.

Nesses cursos, dispensa-se grande atenção a métodos de ensino, aplicação da metodologia em aulas de demonstração, psicologia educacional, desenvolvimento e produção de materiais de ensino. Paralelamente, é ministrado um curso avançado de Psicologia Educacional, destinado ao aperfeiçoamento ou outros assuntos não relacionados com publicações deverá ser enviados para:

Diretores Técnicos do PABAEE

Instituto de Educação - Sala 3

Rua Pernambuco Belo Horizonte, MG

$\mathrm{Na}$ apresentação do documento podemos observar que os objetivos oficiais propostos pelo Programa estavam centrados em torno do aperfeiçoamento dos professores que nesse período eram, em grande número, leigos, além das normalistas e os regentes de ensino.

Em maio de 1957 novos os objetivos são incorporados ao Programa:

1. Introduzir e demonstrar aos educadores brasileiros métodos e técnicas empregadas no campo do ensino primário, submetendo-os à análise, aplicação e adaptação para satisfazer às necessidades da comunidade no campo da educação, estimulando as iniciativas dos professores no sentido do aperfeiçoamento e contínuo desenvolvimento do Programa.

2. Criar, apresentar e adaptar o material didático, assim como o equipamento, baseando-se nas possibilidades resultantes da análise dos materiais e equipamentos disponíveis no Brasil e demais lugares, apropriados ao campo da educação elementar.

3. Selecionar destacados professores, segundo sua competência profissional, conhecimento e eficiência no uso da língua inglesa, para serem enviados aos Estados Unidos para um curso avançado de aperfeiçoamento de métodos de ensino elementar (HART; RENAULT, 1957 apud PAIVA; PAIXÃO, 2002, p. 78-79).

Para cumprir tais objetivos estava previsto que o Programa seria desenvolvido até o ano de 1961, porém acordos posteriores (com a difusão do PABAEE em todo território nacional) levaram a duração dessa assistência até 1º de agosto de 1964 que continuou sob-responsabilidade do INEP. 
Paiva e Paixão (2002) comentam que no final do mês de agosto de 1963 o governo dos Estados Unidos comunicou a decisão de encerrar sua contribuição ao fundo que financiava o Programa, nesse sentido, no mês de setembro do mesmo ano o PABAEE passa a ser integrado ao Centro Regional de Pesquisa Educacional (CRPE) de Minas Gerais, tornando-se vinculado apenas ao INEP. Por mais algum tempo a sigla PABAEE continuou sendo usada por conta da alta difusão que o Programa havia alcançado.

Os materiais didáticos produzidos para o aperfeiçoamento da professora primária eram repletos de prescrições e atividades para os planejamentos de aulas, dado que os materiais que estavam sendo utilizados nas escolas primárias, até então, eram considerados inadequados, não contribuindo para o bom desempenho educacional.

Foi neste ambiente que o filme $A$ escola agora é outra, produzido pelo estúdio da Herbert Richers ${ }^{10}$ e divulgado pela Distribuidora de Filmes Sino, foi produzido. Tratou de apresentar o PABAEE, seus objetivos e relatar o que era, no olhar de seus técnicos, os maiores problemas da escola elementar brasileira. $\mathrm{O}$ audiovisual era apresentado durante os cursos de aperfeiçoamento oferecido às professoras como um recurso didático.

O Programa, em certa medida, foi acompanhado de resistências por parte de alguns grupos, mas em contrapartida houve um grande investimento para que a assistência se tornasse uma referência em dimensões nacionais. Assim, um dos objetivos era fortalecer o PABAEE, levando-o para todos os estados brasileiros.

Em meados de agosto de 1958 foi previsto um curso de maior duração para professores considerados mais destacados das Escolas Normais a serem selecionados em todo o país. Para esse curso, tinha-se como objetivo promover uma formação de alto nível, com duração de um semestre para as Escolas Normais mais importantes do país, oportunizando conferências para líderes educacionais sobre o PABAEE e formação de professores, além de disponibilizar um programa de bolsa que possibilitaria a participação de treinamentos nos EUA.

O curso para o programa de bolsa de estudos no Brasil é a primeira atividade do PABAEE planejada para uma cobertura em âmbito nacional. As principais Escolas Normais das diversas regiões do país foram convidadas pelo INEP a enviarem grupos de três participantes. O curso começou no dia 6 de outubro [de 1958] (PAIVA; PAIXÃO, 2002, p. 110).

Por meio da realização desse curso, o Programa certamente ganhou maior visibilidade, atingindo várias Escolas Normais e promovendo o contato de professores/ as, diretores/as com as novas metodologias apresentadas, como também a aproximação com a experiência norte-americana em educação.

Dois anos depois, o PABAEE encontrava-se ainda mais fortalecido, com melhor atuação e visibilidade, como bem citou Paiva e Paixão (2002, p. 129): 
No início dos anos de 60, o PABAEE encontrava-se em pleno funcionamento, e tinha seu trabalho reconhecido por setores relacionados ao ensino primário. Seu quadro de pessoal ampliara-se. Trabalhavam no Programa 31 técnicos brasileiros, oito americanos e aproximadamente 48 funcionários.

Atendendo aos objetivos propostos, o PABAEE alcançou grande parte dos estados brasileiros, atingindo 864 bolsistas, além de 8 venezuelanos e 24 paraguaios. Foram distribuídas 142 bolsas de estudos para universidade norte- americanas das quais 130 para a Universidade de Indiana (EUA) e 12 em outras universidades (PAIVA; PAIXÃO, 2002). O quadro abaixo traz a distribuição das bolsas por estado.

Quadro 1 - Número de bolsas de estudos do PABAEE por estados brasileiros (1959-1964)

\begin{tabular}{|c|c|}
\hline \multicolumn{2}{|c|}{ ESTADOS E QUANTIDADE DE PARTICIPANTES } \\
\hline Acre (18) & Paraná (22) \\
\hline Alagoas (30) & Pernambuco (40) \\
\hline Amapá (4) & Piauí (15) \\
\hline Amazonas (8) de Janeiro (8) \\
\hline Bahia (33) & Rio Grande do Norte (42) \\
\hline Ceará (25) & Rio Grande do Sul (29) \\
\hline Distrito Federal (48) & Santa Catarina (19) \\
\hline Espirito Santo (49) & São Paulo (77) \\
\hline Minas Gerais (203) & Sergipe (21) \\
\hline Pará (2) & Goiás (48) \\
\hline Paraiba (26) & Maranhão (11) \\
\hline Guanabara (18) & \\
\hline Mato Grosso (21) & \\
\hline
\end{tabular}

Fonte: Elaborado pelas autoras (2016), com base no livro de Paiva; Paixão (2002, p. 150).

$\mathrm{Na}$ sequência da discussão apresentaremos algumas análises e problematizações a respeito do filme, conforme o que foi anunciado na introdução deste artigo. 


\section{A escola agora é outra: o filme}

Para além de formar professoras e produzir materiais didáticos, o PABAEE propunha uma ruptura com o modelo educacional vigente, considerado ineficaz e ultrapassado.

A escola era vista como pouco atrativa e repleta de reprovações e baixo desempenho, o que, na visão dos protagonistas do convênio, desencadeava inúmeros problemas para educação brasileira. O filme, apresentado pelo PABAEE, simulava uma escola com ensino prático, com equipamentos escolares adequados, tendo a criança como centro do aprendizado.

Essa preocupação certamente estava pautada no movimento escolanovista, que buscou enfatizar os "métodos ativos" de ensino-aprendizagem, propondo liberdade à criança a partir de seu interesse. Também adotou métodos que ampliavam a participação das mesmas, incentivando atividades práticas e trabalhos manuais. A Escola Nova deu grande importância para o campo da psicologia experimental.

Assim, o PABAEE apresentava-se como uma solução para as professoras primárias, na medida em que oferecia estratégias didáticas inovadoras, repletas por preceitos que anunciavam e prometiam uma "boa educação". Nesse processo, podemos inferir que houve a tentativa de categorizar os/as alunos/as em civilizados/as, aqueles que frequentavam a escola, e incivilizados os que não tinham acesso a ela, ou os que tinham acesso, mas não se enquadravam no novo modelo educacional.

Sobre o processo civilizador, Norbert Elias (2011, p. 78) afirma que "o que achamos inteiramente natural, porque fomos adaptados e condicionados a esse padrão social desde a mais tenra infância, teve, no início, que ser lenta e laboriosamente adquirido e desenvolvido pela sociedade como um todo". Nessa perspectiva, a escola torna-se uma das instituições responsáveis em educar as crianças com o objetivo de moldar comportamentos de acordo com os objetivos de cada sociedade, circunscrita em determinado tempo e espaço.

O filme monocromático (preto e branco), ambientado em uma pequena cidade de Minas Gerais, busca mostrar como as orientações do PABAEE poderiam ser úteis às professoras. Com duração de 10 minutos e 37 segundos, inicia com a seguinte manifestação:

\footnotetext{
A escola agora é outra

O que aconteceu com as crianças dessa cidade do interior de Minas, poderá acontecer com as crianças da sua cidade também.

Assim, naturalmente, as crianças vão à escola, freqüentam o grupo porque o progresso de qualquer comunidade está diretamente ligado à educação dos jovens (DISTRIBUIDORA DE FILMES SINO RICHERS, S/D).
}

Percebe-se que o PABAEE, por meio de seu discurso, pauta-se na centralidade da escola no processo de civilização das crianças, a fim de garantir o progresso do país. Para isso, a racionalização e regramento dos comportamentos eram imprescindíveis, sendo a escola um espaço privilegiado para esse objetivo. 
A escolha do título $A$ escola agora é outra faz alusão às mudanças prescritas pelo Programa, de transformar a escola ineficaz em uma escola moderna, com métodos e estratégias de ensino dinâmico para envolver as crianças nas aulas. Entretanto, diante da narrativa que apresenta crianças desmotivadas em sala de aula, algumas questões emergem: até que ponto a escola anunciada pelo Programa é nova? Ou ainda, até que ponto a escola vigente poderia ser considerada atrasada? Como as professoras vinham trabalhando até então? Será que elas já não vinham construindo suas próprias metodologias e inovando suas práticas? Em que medida as escolas estavam preparadas, tanto em sua infraestrutura quanto com recursos materiais, para desenvolver aulas mais interessantes?

Em seguida, o filme apresenta o recreio escolar com as crianças brincando de "pular carniça" ${ }^{11}$, cantando cantigas de roda como "ciranda cirandinha", "o anel que tu me deste", entre outras brincadeiras. Esta cena contrasta com o trabalho de sala de aula realizado pela professora, pois as crianças aparecem desanimadas e pouco interessadas no conteúdo explicado. Há um antagonismo entre o comportamento das crianças dentro e fora da sala de aula.

Após o recreio as crianças voltam para sala de aula, mas como se ainda estivessem no intervalo, em tom de repressão o narrador faz alguns questionamentos:

Como toda criança, essas também gostam de brincar...

Acabou-se o que era doce. Acabou-se o recreio.

Agora criançada vamos estudar!

Afinal o recreio acabou ou não acabou?

Vamos, acordem!

Agora que está tudo explicado, vamos ver quem aprendeu.

Davi, você entendeu a explicação? (DISTRIBUIDORA DE FILMES SINO RICHERS, S/D).

As crianças continuam brincando com aviões de papel, dormem na sala de aula, enquanto a professora insiste em perguntar sobre a lição, não obtendo respostas. Neste momento, o filme procurando demonstrar que as crianças apenas brincavam e nada aprendiam. As cenas expõem ainda certo desespero, frustração e até mesmo a falta de domínio da professora frente à turma. Em outras palavras, retrata a escola como um verdadeiro caos e a professora totalmente despreparada para lidar com o processo ensino aprendizagem. 
Figura 1 - Cena do filme A escola agora é outra

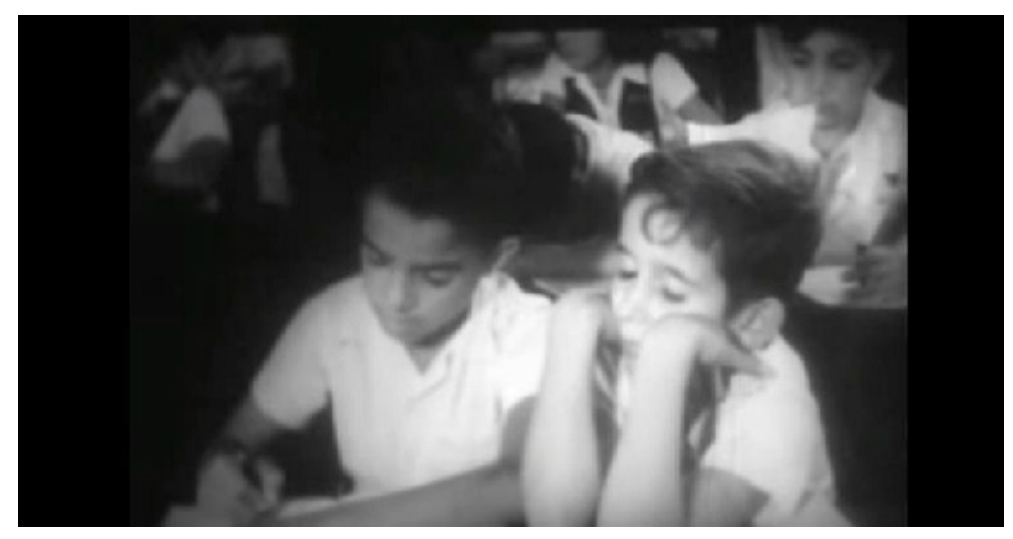

Fonte: Disponível em: https://www.youtube.com/watch?feature=player_detailpage\&v=IQMXyTf_aQQ

O filme coloca sobre a professora primária uma grande responsabilidade. Além de ensinar os conteúdos programáticos, ela deveria atuar para a mudança de comportamentos.

$\mathrm{Na}$ sequência, o filme exibe uma aula de Geografia de forma irônica e nesse sentido o narrador faz provocações:

\section{Geografia ou trabalhos manuais?}

Seja como for, não há dúvidas que esses garotos são fãs da aviação.

Tem nitidamente vocação a aeronáutica, porém como pilotos não foram bem sucedidos (DISTRIBUIDORA DE FILMES SINO RICHERS, S/D).

A cena mostra um grupo de meninos fazendo aviões de dobraduras em papel. A professora está escrevendo o conteúdo no quadro negro, enquanto isso as crianças seguem com as brincadeiras. A aula parece ser desinteressante e as mesmas não acompanham as lições, reforçando as cenas anteriores, onde as aulas são apenas focadas nos conteúdos, tornando-se assim pouco atrativas.

Novamente a professora é culpabilizada pelo caos presente na sala de aula, pois ela não consegue atrair a atenção das crianças em relação ao conteúdo que está ensinando. Neste contexto, a criança está apática e sem interesse algum, mas por conta da falta de habilidade da professora e falta de material didático. Em outras palavras: ela não conseguia ensinar porque não conseguia atrair o interesse das crianças. Diante desta confusão na sala de aula, o narrador faz as seguintes questões:

Finalmente chegou a hora de ir para casa.

Por que será que essas crianças não aprendem a lição?

Por que será?

Por que será Diretor? (DISTRIBUIDORA DE FILMES SINO RICHERS, S/D). 
Essas questões só poderiam ser respondidas pelos técnicos do PABAEE, pois no filme é retirada a credibilidade da escola e das professoras, transferindo a solução para o Programa. A segunda parte do filme apresenta um grupo de professoras em reunião, quando essa pergunta é dirigida à inspetora regional: "Por que será que essas crianças não aprendem as lições?” Ela não soube responder sobre as causas dessa situação tão recorrente nas escolas primárias, na visão dos técnicos do PABAEE. Para solucionar os problemas vivenciados o narrador do filme aponta um caminho:

A inspetora teve uma ideia: daria um pulinho até Belo Horizonte. Ela ouvira falar do Programa de Assistência Brasileiro-Americana ao Ensino Elementar, comumente denominado PABAEE, com sede no Instituto de Educação.

O PABAEE era uma entidade constituída por equipe de educadores brasileiros, que trabalham com técnicos do Ponto IV para elevar o padrão do ensino primário.

Por isso ela veio até o PABAEE em busca de ajuda. Isso inspetora. Os objetivos do PABAEE: aprimorar os métodos do ensino elementar; aperfeiçoar professores e colaborar na produção e divisão de materiais de auxílio didáticos (DISTRIBUIDORA DE FILMES SINO RICHERS, S/D).

O filme sustenta a ideia de que os problemas educacionais só poderiam ser solucionados por meio do aperfeiçoamento das professoras e a difusão das técnicas e metodologias propostas pelo PABAEE.

O que antes não funcionava poderia dar certo com as estratégias adequadas, por exemplo, com a valorização da brincadeira, ou seja, as crianças poderiam aprender brincando. A valorização tanto das atitudes espontâneas quanto das experiências e conhecimentos individuais das crianças, bem como a própria aprendizagem em grupo, demonstram a circulação do ideal pragmatista de John Dewey, que pode ser observado também na seguinte frase: "O bom ensino é baseado no interesse das crianças".

Tais aspectos eram entendidos como inovações pedagógicas que permitiriam uma formação global, que não estava centrada apenas no conteúdo, no intelecto, mas sim em aspectos sociais como a formação da personalidade. Nessa proposta a professora não é o centro, ela está apenas guiando as crianças para novas descobertas.

É sabido que o movimento da Escola Nova repercutiu no Brasil entre as décadas de 1920 e 1930, seu debate contestava os padrões da escola tradicional, em que "o trabalho dos alunos se caracterizava por uma atitude de receptividade ou absoluta passividade: um professor que falava e discípulos que deveriam ouvir em silêncio, imóveis, de braços cruzados." (LOURENÇO FILHO, 1978, p. 151).

No filme metodologias são ensinadas às professoras e o narrador informa:

Professores das mais variadas tendências têm procurado o PABAEE para aprimorar seus métodos de ensino, através, por exemplo, de alguns auxílios visuais.

Um mapa assim, feito com cartão perfurado, um apagador e um pouco de giz tem o dom de interessar as crianças e permitir que elas 
Exemplos também são mencionados em relação ao ensino de Aritmética, como alguns recursos didáticos produzidos com papelão e pregadores de roupa, a fim de facilitar a aprendizagem. Demonstra ainda que com os cursos de aperfeiçoamento do PABAEE e a produção de matérias didáticos de baixo custo as professoras poderiam superar dificuldades vivenciadas em seu trabalho.

Após demonstrar um grupo de professoras realizando curso de aperfeiçoamento, aponta uma cena totalmente diferente da sala de aula comparada com as cenas iniciais: uma sala organizada com crianças atentas e acompanhando as lições. Em relação a este aspecto o narrador discorre:

Quando a professora perguntou quem queria ir à pedra, ninguém quis se esconder Foi difícil escolher, até o Zezinho se ofereceu!

Partindo do concreto para o abstrato a multiplicação se tornou muito mais fácil! Qualquer criança aprendia! (DISTRIBUIDORA DE FILMES SINO RICHERS, S/D).

Tal episódio pode ser articulado com as reflexões críticas realizadas por Libâneo (1990) à escola nova a partir da ideia do "aprender fazendo", que em seu entendimento estava no âmbito da tendência liberal de educação.

Retomando o filme, os exemplos de bom comportamento e disciplina seguem, após a minuciosa instrução do PABAEE:

Vejamos como anda a Geografia.

[...] Também mudou, deixou de ser aquela aula maçante de decorador de nomes, agora as crianças participam com entusiasmo da lição. (DISTRIBUIDORA DE FILMES SINO RICHERS, S/D).

Essa mudança de comportamento das crianças e do alcance do trabalho da professora pode ser analisados na perspectiva liberal, pois nela "[..] aprender se torna uma atividade de descoberta, é uma auto-aprendizagem, sendo o ambiente apenas o meio estimulador" (LIBÂNEO, 1990, p. 12-13).

Como em um passe de mágica, o final do filme apresenta as crianças felizes e calmas, saindo da escola de forma ordenada:

Agora as crianças não deixam mais a escola como fugitivos, mas com satisfação.

As professoras sentem-se recompensadas pelo esforço despendido;

Até amanhã professora! Até amanhã crianças!

Os acenos se repetem prolongando a despedida.

Até amanhã crianças!

Porque amanhã a escola fará de vocês os novos líderes!

Cidadãos dignos e úteis a sociedade! 
Amanhã vocês não podem faltar!

Porque amanhã crianças vocês tem um encontro marcado com o futuro! (DISTRIBUIIDORA DE FILMES SINO RICHERS, $\mathrm{S} / \mathrm{D})$.

Em suma, o filme demonstra como o PABAEE poderia ajudar a transformar a realidade educacional das escolas brasileiras por meio dos novos métodos, materiais didáticos criativos e modernos. O filme coloca o PABAEE como a solução para os problemas educacionais e normatizador de uma conduta de comportamento, transformando as crianças agitadas em calmas, desorganizadas em interessadas e, além disso, busca instrumentalizar as professoras para serem capazes de oferecer aulas mais eficientes e interessantes para as crianças.

De acordo com as autoras Paiva e Paixão (2002), a exibição do filme gerou diferentes reações, pois algumas professoras denunciaram situações apresentadas nas cenas que não condiziam com a realidade. As professoras alegaram que as cenas teriam sido preparadas para demonstrar salas de aula bagunçadas com crianças desinteressadas e professoras desmotivadas e inexperientes. Tal fato provocou a revolta de professores/as, que passaram a olhar o Programa com certa hostilidade e desconfiança, contribuindo para aumentar o desgaste do PABAEE no campo educacional brasileiro.

\section{Considerações finais}

Compreender o que foi o PABAEE e a sua magnitude sem dúvida não é uma tarefa simples, pois muitas são as questões que envolvem o Programa, o fato de ser fruto do acordo entre Brasil e Estados Unidos, ter alcançado uma vasta abrangência em território nacional, possuir uma produção didática para auxiliar no aperfeiçoamento da professora primária, contribuindo para a divulgação e consolidação de uma pedagogia considerada moderna, entre outras realizações. Ao mesmo tempo, revela outra face, pois foi pouquíssimo estudado na área da História da Educação e pouco mencionado nos documentos oficiais como parte da trajetória das campanhas educacionais. Inclusive na revista de comemoração dos 70 anos do INEP são feitas apenas algumas considerações em relação ao Programa.

Entretanto, pudemos, ao longo da pesquisa, nos aproximar do contexto educacional da época e compreender que o PABAEE não foi um simples programa educacional, ele expressou discursos que apregoavam a necessidade da formação do cidadão para a sociedade moderna.

O filme $A$ escola agora é outra não apenas apresentou o PABAEE como uma solução dos problemas para educação brasileira, buscando reforçar o papel que a escola deveria cumprir no processo de modernização e a centralidade do trabalho da professora, mas apontou para a necessidade de uma nova escola, com métodos ativos, com equipamentos escolares adequados, evidenciando que a escola vigente estava atrasada e era pouco atrativa. Além disso, culpabilizou a professora primária pelos baixos índices educacionais. 
A escola era vista como meio de superação do atraso social, portanto, possuir instrução, ser alfabetizado, ter bons modos garantiriam a vida em sociedade às crianças, futuros cidadãos da nação brasileira. Ao mesmo tempo em que proclamava a vida em democracia e em comunidade, essa proposta de escola parece ter sido pouco democrática, visto que as experiências pedagógicas não atingiram grande parte das escolas públicas.

Saviani (2005), ao criticar alguns aspectos da Escola Nova, menciona que esta apresentou, em certo momento, um "entusiasmo pela educação" refletido no lema "Escola para Todos", sendo que esse era o grande lema da luta dos escolanovistas. Para o autor, advogar escola para todos correspondia ao interesse da burguesia, era importante para ela manter a ordem democrática, e era importante para o operariado, porque para este segmento representava participar de alguma forma do processo político e das decisões.

Portanto, o modelo de escola em que o PABAEE estava inspirado era baseado na consolidação do modelo capitalista, não apresentando críticas ao modelo social excludente, às desigualdades, mas sim reforçando-as.

Dessa forma, o hábito de ser cortês, pedir a vez, aprender a socializar-se constituiu modelos comportamentais que deveriam ser aprendidos não apenas para serem postos em prática no ambiente escolar, mas levados para a vida em sociedade, afinal um bom comportamento poderia se refletir na "boa escolha dos governantes" ou em não questionar as desigualdades sociais vigentes. A partir das análises pudemos identificar alguns indícios das regras e os preceitos voltados à regulação dos comportamentos (hábitos de asseio pessoal, prescrições de leitura, maneiras de portar-se), que tinham como objetivo a construção de práticas de convívio/sociabilidade, objetivando a formação de cidadãos bem-educados e mais produtivos.

Retomando as reflexões sobre o audiovisual analisado nesse estudo, podemos considerar que haviam intencionalidades inseridas em um contexto e que pretendiam revelar a existência de situações que necessitavam da intervenção do PABAEE. Ao mesmo tempo que se representava uma sala de aula com resultados pouco proveitosos, contrapunha-se uma imagem do Programa como uma salvação para os problemas educacionais brasileiros. Tal construção imagética nos obriga a ir além da "ilustração" e ir em busca de outros documentos a fim de abrir novas possibilidades para o nosso trabalho historiográfico no campo da história da educação.

\section{Referências}

BLACK, Lloyd D. A estratégia de ajuda externa. Tradução de Carlos Nayfeld. Rio de Janeiro: O Cruzeiro, 1968.

BRASIL. Convenção sobre o Banco Internacional para a Reconstrução e Desenvolvimento (Banco Mundial) Promulgado pelo Decreto no 21177 de 27 de julho de 1946. Disponível em: http://dai-mre.serpro.gov.br/atos-internacionais/multilaterais/convencao-sobre-o-banco-internacional-para-a-reconstrucao-e-desenvolvimento-banco-mundial/.

CHARTIER, Roger. Textos, impressões, leituras. In: HUNT, Lynn. A nova história cultural. São Paulo: Martins Fontes, 1992. 
ELIAS, Norbert. O Processo Civilizador: uma História dos Costumes. 2 ed. Rio de Janeiro: Zahar, 2011.

IANNI, Octávio. Estado e planejamento econômico no Brasil (1930-1970). 2 ed. Rio de Janeiro: Civilização Brasileira, 1996.

LE GOFF, J. História e Memória. São Paulo: Ed. Unicamp, 2003.

LIBÂNEO, José Carlos. Democratização da Escola Pública: a pedagogia crítico-social dos conteúdos. São Paulo: Loyola, 1990.

LOURENÇO FILHO, M. B. Introdução ao estudo da Escola Nova. 13. ed. São Paulo: Edições Melhoramentos, 1978

MOREIRA, Antonio Flavio Barbosa. Currículos e programas no Brasil. Campinas, SP: Papirus, 1990.

NOGUEIRA, Martha Guanaes. Supervisão Educacional: a questão política. Ed. Loyola, São Paulo, Brasil, 1989.

PINSKY, Carla Bassanezi (org.). Fontes históricas. São Paulo: Contexto, 2005, 302p.

PAIVA, Edil Vasconcellos de; PAIXÃO, Lea Pinheiro. PABAEE (1956 - 1964): a americanização do ensino elementar no Brasil? Niterói: EdUFF, 2002.

SAVIANI, Demerval. As concepções pedagógicas na História da Educação Brasileira. Texto elaborado no âmbito do projeto de pesquisa "O espaço acadêmico da pedagogia no Brasil", financiado pelo CNPq, para o "projeto 20 anos do Histedbr". Campinas, 25 de agosto de 2005.

Notas

1 Projeto aprovado no edital MCTI/CNPQUniversal 14/2014, coordenado pela professora Dra. Giani Rabelo.

2 Clóvis Salgado foi Ministro da Educação e Cultura de (31/01/1956 a 31/01/61).

3 Disponível em: https://www.youtube.com/watch?feature=player_detailpage\&v=IQMXyTf_aQQ.

4 Neste caso o autor estaria sendo representado pelos técnicos do PABAEE que colaboraram para a elaboração do filme.

5 Neste caso o público alvo do filme, ou seja, as professoras do primárias.

6 Lúcia Casasanta, era professora da Escola de Aperfeiçoamento, que mais tarde passou a ser Curso de Administração Escolar, teve influência considerável na qualificação dos supervisores de ensino mineiros e na divulgação do método global, abordagem que defendia de acordo com a qual escreveu e publicou material didático para alfabetização largamente utilizado nas escolas primárias mineiras.

7 José Francisco Bias Fortes.

$8 \mathrm{Na}$ reforma organizada por Francisco Campos e Mário Casassanta, em Minas Gerais, o pensamento da Escola Nova aparece sistematizado com clareza. Essa reforma, que procurou reorganizar os ensinos elementar e normal, é considerada por Nagle (1974) como primeiro momento de uma abordagem técnica de questões educacionais no Brasil (MOREIRA, 1990, p. 89).

9 A coleção Biblioteca de Orientação da Professôra Primária é composta pelos seguintes títulos: Ver, sentir, descobrir a Aritmética, Experiências de Linguagem Oral, Formação e Desenvolvimento de Conceitos, O que é Jardim de Infância, Testes, Medidas e Avaliação Ciências na Escola Moderna, Habilidades de Estudos Sociais. 
10 Herbert Richers foi um importante produtor de cinema brasileiro, que fundou a empresa Herbert Richers S.A. Tornou-se muito conhecido por seu forte relacionamento com os estúdios de Hollywood, e com os estúdios da Walt Disney, onde aprendeu as técnicas de dublagens, e ao trazer ao Brasil começou a aplicar nos filmes exibidos na TV.

11 Nesta brincadeira uma criança fica abaixada e as outras pulam passando por suas costas, o líder da brincadeira dá um comando e todas as crianças devem realizar os comandos, que variam entre socos, beliscões, bater, catar piolho (fingir que cata piolho), entre outros. Podemos observar que é uma brincadeira bastante violenta, e o fato do filme comentar que as crianças tinham o hábito de praticar tal brincadeira pode ser entendido como uma crítica dos produtores do filme em relação ao comportamento que as crianças tinham antes do PABAEE.

* Doutoranda do Programa de Pós-Graduação em Educação da Universidade do Estado de Santa Catarina, Florianópolis, Santa Catarina, Brasil.

** Professora doutora da Universidade do Extremo Sul Catarinense, Criciúma, Santa Catarina, Brasil.

\section{Correspondência}

Giani Rabelo - Universidade do Extremo Sul Catarinense/SC, Programa de Pós-graduação em Educação. Av. Universitária, 1105, Bairro Universitário. CEP: 88806-000. Criciuma, Santa Catarina, Brasil.

E-mail:sucosta@unesc.net-gra@unesc.net

Recebido em 11 de julho de 2017

Aprovado em 16 de outubro de 2017 
